\begin{tabular}{|c|l|}
\hline Title & Oxygen Reduction Reaction Catalyzed by Small Gold Cluster on h-BN/Au(111) Support \\
\hline Author(s) & Lyalin, A ndrey; U osaki, Kohei; Taketsugu, Tetsuya \\
\hline Citation & $\begin{array}{l}\text { Electrocatalysis, 9(2), 182-188 } \\
\text { https:/doi.org/10.1007/312678-017-0395-5 }\end{array}$ \\
\hline Issue Date & 2018-03 \\
\hline Doc URL & http://hdl.handle.net/2115/72710 \\
\hline Rights & The final publication is available at link.springer.com. \\
\hline Type & article (author version) \\
\hline File Information & Iyalin-Au__v2.pdf \\
\hline
\end{tabular}

Instructions for use 


\title{
Oxygen Reduction Reaction Catalyzed by Small Gold Cluster on h-BN/Au(111) Support
}

\author{
Andrey Lyalin - Kohei Uosaki - Tetsuya Taketsugu
}

Received: date / Accepted: date

\begin{abstract}
The catalytic activity for the oxygen reduction reaction (ORR) of a hexagonal boron nitride (h$\mathrm{BN})$ monolayer deposited on a $\mathrm{Au}(111)$ surface and decorated by a small planar $\mathrm{Au}_{8}$ cluster has been studied theoretically using density-functional theory. It is shown that gold nanoparticles (Au-NP) deposited on the h-BN/Au(111) surface can provide catalytically active sites for effective ORR at the perimeter interface with the support. Stabilization of oxygen at the perimeter interface between Au-NP and h-BN/Au(111) support promotes $\mathrm{OOH}^{*}$ dissociation opening effective 4electron pathway of ORR with formation of $\mathrm{H}_{2} \mathrm{O}$. It is suggested that increase in the perimeter interface area between the supported Au-NP and the surface would result in increase of the ORR activity. Such increase in the perimeter interface area can be achieved by decreasing the size of Au-NP. Our calculations demonstrate the principal ability to functionalize inert materials such as stand-alone h-BN monolayer or Au surface for the ORR and open new way to design effective Pt-free catalysts for fuel-cell technology.
\end{abstract}

Keywords Boron Nitride - Gold Nanocatalysis · Oxygen Reduction Reaction · Interface Effects

A. Lyalin · K. Uosaki · T. Taketsugu

Global Research Center for Environment and Energy based on Nanomaterials Science (GREEN), National Institute for Materials Science (NIMS), Tsukuba 305-0044, Japan

E-mail: lyalin.andrey@nims.go.jp

T. Taketsugu

Department of Chemistry, Faculty of Science, Hokkaido University, Sapporo 060-0810, Japan

E-mail: take@sci.hokudai.ac.jp

\section{Introduction}

Development of the effective electrocatalyst for oxygen reduction reaction (ORR) is one the most important problems in fuel cell technology [1-6]. Currently, the most efficient electrocatalysts for the ORR are based on platinum which prevents the wide use of fuel cells in practical applications for energy conversion due to the high cost and limited resources of platinum. Therefore worldwide efforts are directed towards the search for principally novel electrocatalysts for ORR based on low cost and abundant materials.

It is well known that the wide range of materials can demonstrate promising activity for ORR including non-precious metals and their alloys with platinum [1,7-9], metal oxides [10,11], metal nitrides [12], metal oxynitrides $[13,14]$, metal carbides $[10,12,15]$, metalnitrogen-carbon (MNC) electrocatalysts [16-19], metal dichalcogenides [20,21], and N- and B-doped carbon materials with and without metal doping [22-30], etc.

It has been demonstrated that in the carbon-based nanomaterials such as graphene sheets doped with $\mathrm{N}$ and $\mathrm{B}$ atoms, BN-pair impurities can serve as active sites for the ORR $[28,31]$. This is interesting fact, because steadily increasing concentration of BN-pairs in the graphene sheet in the limit case one can substitute all carbon atoms by boron and nitrogen and obtain hBN monolayer which has a similar geometry structure as graphene, but principally different electronic and chemical properties. h-BN is often used in nanocatalysis as an inert support which does not affect the electronic and geometry structure of the deposited nanoparticles and hence does not affect their chemical reactivity. Indeed, h-BN is an electrical insulator with a wide band gap and high thermal and chemical stability $[32,33]$. Therefore until recently such material has never been 
considered as a possible candidate for electrocatalyst. However in our previous works we have demonstrated theoretically that $\mathrm{h}-\mathrm{BN}$ is not as inert as it was previously believed and can strongly affect the catalytic properties of the supported metal particles [34-38].

Moreover, we have predicted that h-BN monolayer modified by doping or metal support can demonstrate catalytic activity for ORR [39-41]. Indeed, the band gap in a h-BN monolayer can be considerably reduced by various type of defects $[39,42,43]$, and it was demonstrated that a h-BN monolayer deposited on the transitionmetal support can be a conductor under certain conditions due to metal-d $\mathrm{BN}-\pi$ hybridization at the h$\mathrm{BN} /$ metal interface and formation of the gap states [4446]. It is important to note that adsorption energies of intermediates of catalytic reactions can be strongly affected by the density of electronic states (DOS) near the Fermi level. Therefore, a metal substrate or defects in h-BN can promote or affect catalytic reactions on the h-BN surface [38]. This theoretical suggestion has been proved experimentally where it has been demonstrated that $\mathrm{Au}$ electrodes modified with boron nitride nanosheet (BNNS) in the acid media indeed can act as effective electrocatalysts not only for ORR $[47,48]$, but also for the hydrogen evolution reaction (HER) [49]. It has been demonstrated that overpotential for ORR at gold electrode is reduced by $0.27 \mathrm{~V}$ by the modification with BNNS, although it is still high compared with $\mathrm{Pt}$ electrode and oxygen is mainly reduced to $\mathrm{H}_{2} \mathrm{O}_{2}$ via 2electron process $[47,48]$. Calculations demonstrate that in the case of $\mathrm{Au}$ electrode covered by h-BN monolayer the desired 4-electron process leading to formation of $\mathrm{H}_{2} \mathrm{O}$ is not energetically favorable due to stability of $\mathrm{OOH}^{*}$ towards dissociation into $\mathrm{O}^{*}$ and $\mathrm{OH}^{*}$ (here $*$ denotes the adsorbed species) [47]. It is important to note that the pure $\mathrm{Au}$ electrode has very weak ORR activity, while stand-alone h-BN is inert, therefore interaction between $\mathrm{h}-\mathrm{BN}$ and $\mathrm{Au}$ plays the key role for ORR $[47,48]$. Thus, one can suggest that increase in h-BN-Au interaction and formation of adsorption sites on the h-BN/Au surface for stabilization of the $\mathrm{O}^{*}$ and $\mathrm{OH}^{*}$ intermediates relatively to $\mathrm{OOH}^{*}$ can open 4-electron channel for ORR [50]. One of the methods to increase h-BN-Au interaction and create additional adsorption sites for $\mathrm{O}^{*}$ and $\mathrm{OH}^{*}$ intermediates is decoration of the h-BN/Au surface by small $\mathrm{Au}$ nanoparticles. It is well known that small $\mathrm{Au}$ nanoparticles demonstrate extraordinary catalytic activity for $\mathrm{O}_{2}$ activation and selective oxidation by molecular oxygen [51-54]. In this case catalytic reactions often occur at the interface area between the supported gold nanoparticle and the surface [55]. Therefore deposition of gold clusters on h-BN/Au surface can considerably promote
ORR. Indeed it was shown experimentally that decoration of $\mathrm{h}-\mathrm{BN} / \mathrm{Au}$ electrode with $\mathrm{Au}$ nanoparticles not only opens the 4-electron ORR pathway leading to formation of water, but also reduces overpotential by ca. $50 \mathrm{mV}[50]$.

In the present work we perform systematic theoretical analysis of the observed phenomena on the example $\mathrm{Au}_{8}$ cluster which mimics very small and flexible gold nanoparticle on the h-BN/Au surface. It is demonstrated that the perimeter interface between the gold nanoparticle and h-BN/Au surface forms active sites for oxygen adsorption promoting $\mathrm{OOH}^{*}$ dissociation in this area, which in turn opens 4-electron pathway for oxygen reduction. Therefore we suggest that increase in the perimeter interface area at the boundary of the deposited Au nanoparticles and h-BN/Au support would result in increase of the ORR activity of such catalyst. The increase in the perimeter interface area can be achieved by decrease in size of $\mathrm{Au}$ nanoparticles. This effect is well known in gold nanocatalysis for various oxidation and hydrogenation reactions [55].

\section{Theoretical Methods}

The calculations were carried out using density-functional theory (DFT) with the gradient-corrected exchangecorrelation functional of $\mathrm{Wu}$ and Cohen (WC) [56]. The WC functional provides a good compromise adequately describing energetics of covalent and non-covalent bonds in oxygen and hydrogen molecules, ORR intermediates, as well as the lattice constants, crystal structures and surface energies of solids with layered structures like graphite or h-BN, whose distances between the layers are determined by rather weak interactions [57]. Moreover, the WC functional provides a realistic description of the binding energies and geometries of h-BN layer on top of $3 \mathrm{~d}, 4 \mathrm{~d}$ and $5 \mathrm{~d}$ transition metal surfaces, correctly describing the interaction of transition metals with hBN [57-59]. The WC functional was successfully used in our previous works to describe catalytic activity of BN based stand-alone and supported nanosystems [38$40,47,41,50,49,60]$, and catalytic activity of small gold particles on the pristine and defected h-BN surfaces [35-37].

Double- $\zeta$ plus polarization function (DZP) basis sets were used to treat the valence electrons of all atoms, while the core electrons were represented by TroullierMartins norm-conserving pseudopotentials [61]. Basis set for gold was optimized with the use of the NelderMead simplex method [62]. All calculations were carried out with the use of the SIESTA package [63-65].

Periodic boundary conditions are used for all systems, including free molecules. In the latter case the size 
of a supercell was chosen to be large enough to make intermolecular interactions negligible. The h-BN and $\mathrm{Au}$ lattices have been optimized using the Monkhorst-Pack [66] $10 \times 10 \times 4$ and $10 \times 10 \times 10 \mathrm{k}$-point mesh for Brillouin zone sampling, respectively. The calculated h-BN lattice parameters $\mathrm{a}=\mathrm{b}=2.504 \AA$ and $\mathrm{c}=6.656 \AA$ are in a good agreement with the experimental values of a $=\mathrm{b}=2.524 \pm 0.020 \AA$ and $\mathrm{c}=6.684 \pm 0.020 \AA$, reported in [67]. The calculated lattice parameter of $\mathrm{Au}$ fcc bulk structure is a $=4.1111 \AA$, which is in excellent agreement with the experimental value of $4.0782 \AA[68]$. The optimized lattice of the bulk Au was used to construct four-layer $7 \times 7 \mathrm{Au}(111)$ slab covered by $8 \times 8 \mathrm{~h}-\mathrm{BN}$ monolayer, where the bottom two layers of gold were fixed and all other atoms are fully relaxed. Only the $\Gamma$ point is used for sampling the Brillouin zone of the slab due to the large size of the supercell. The energy cutoff of $200 \mathrm{Ry}$ is chosen to guarantee convergence of the total energies and forces. A common energy shift of $10 \mathrm{meV}$ is applied. The self-consistency of the density matrix is achieved with a tolerance of $10^{-4}$. For geometry optimization the conjugate-gradient approach was used with a threshold of $0.02 \mathrm{eV} \AA^{-1}$. The atoms in molecules method of Bader (AIM) has been used for charge analysis $[69,70]$.

The overall ORR can be written in the following simple form:

$\mathrm{O}_{2}+4 \mathrm{H}^{+}+4 \mathrm{e}^{-} \rightarrow 2 \mathrm{H}_{2} \mathrm{O}$.

A simple description of the ORR mechanism includes investigation of the adsorption preferences of $\mathrm{O}_{2}, \mathrm{OOH}$, $\mathrm{O}, \mathrm{OH}$ and $\mathrm{H}_{2} \mathrm{O}$ intermediates and products on a model catalyst and analysis of the overall energetics for ORR process along the possible reaction pathways. Similar approach has been introduced by Nørskov [71] and described in details by Keith and Jacob [72-74].

It should be noted that in the case of ORR at the transition-metal surfaces activity trends can be considered in terms of the simple descriptors such as the binding energy of chemisorbed oxygen and the shift in the d-band center of the catalyst $[71,75,76]$. Such approach leads to the scaling law where $\mathrm{O}$ and $\mathrm{OH}$ binding energies are roughly linearly correlated for the elemental surfaces [71]. However in the case of ORR at the interface between $\mathrm{BN}$ and $\mathrm{Au}$ bonding of $\mathrm{O}$ and $\mathrm{OH}$ is not necessary should follow the same correlation because these two species can be adsorbed at the different adsorption sites. Such effect can lead to a completely new catalyst.

To describe the energetics of the ORR, we have analyzed the change in free energy, $\Delta G$, along the reaction pathway, which can be done by calculating the heats of formation, $\Delta H_{f}$, and accounting for the change in entropy, $\Delta S$, during the reaction. To simulate ORR under realistic conditions it is also necessary to take into account zero point energy (ZPE) corrections, $\Delta E_{Z P E}$, and the effect of solvent (water) environment on the ORR process, $\Delta E_{\text {water }}$. The overall change in a free energy accounting for the corrections described above can be written in the following form:

$\Delta G=\Delta H_{f}+\Delta E_{Z P E}-T \Delta S+\Delta E_{\text {water }}$,

where $T$ is the temperature of the system.

The heats of formations, $\Delta H_{f}$, can be calculated using information on binding preference and adsorption energies of ORR intermediates [29,71-74,77-80]. In order to obtain the most stable configuration of the adsorbed $\mathrm{O}_{2}$ and ORR intermediates we have generated a large number of starting geometries by adding $\mathrm{O}_{2}, \mathrm{OOH}, \mathrm{O}$ and $\mathrm{OH}$ species in different nonequivalent positions on the surface. The starting structures have been optimized without any geometry constraints. A detailed description of the procedure can be found in our recent works $[39,40]$ and references therein.

\section{Results and Discussion}

3.1 Formation of the active adsorption sites for ORR on the small $\mathrm{Au}_{8}$ cluster supported on h-BN/Au(111)

A free neutral $\mathrm{Au}_{8}$ cluster has a planar two dimensional structure and possesses enhanced stability due to the electronic shell closure effect; see, e.g., [81] and references therein. Therefore it is inert towards adsorption and activation of $\mathrm{O}_{2}$. Nevertheless excess of the negative or positive charge on $\mathrm{Au}_{8}$ can promote its activity towards oxygen activation $[82,83]$. Interaction with the support can induce charge transfer between the cluster and the surface which makes supported cluster more reactive in comparison with its free counterpart [38].

DFT calculations demonstrate that planar $\mathrm{Au}_{8}$ can be adsorbed on the $\mathrm{h}-\mathrm{BN} / \mathrm{Au}(111)$ surface in two different configurations (i) those parallel to the surface with all cluster's atoms atop of B atoms with adsorption energy of $-1.17 \mathrm{eV}$ and (ii) those perpendicular to the surface. The difference in adsorption energy between these two configurations is only $0.06 \mathrm{eV}$, therefore both configurations can coexist at room temperature. We have selected parallel configuration for the further study of the ORR on the supported $\mathrm{Au}_{8}$ because such orientation maximizes the contact area between the cluster and the support, and can serve as a reliable model for the interface area of the larger gold clusters supported on $\mathrm{h}-\mathrm{BN} / \mathrm{Au}(111)$ when two dimensional planar structures are energetically not favorable any more (small 
gold clusters favor planar structures up to cluster size of 12 or 13 atoms, while gold clusters of larger sizes are three dimensional [84-86]). a)

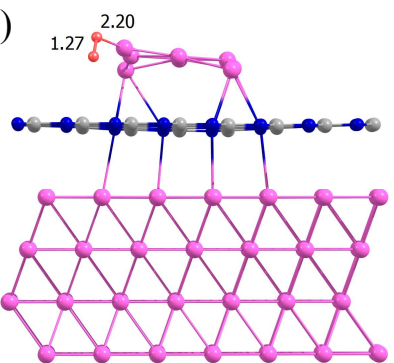

b)

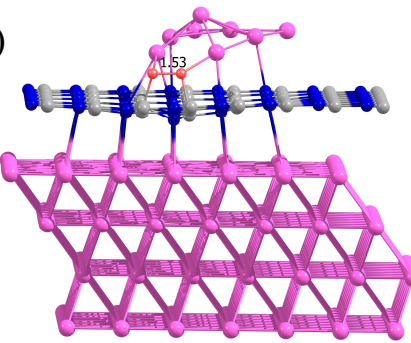

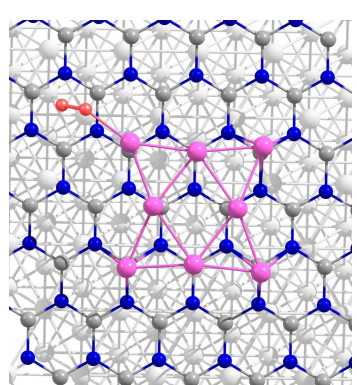

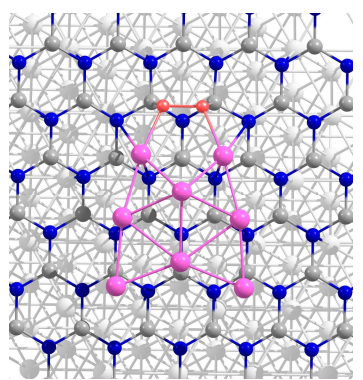

Fig. 1 Side (left) and top (right) views of the optimized geometries of $\mathrm{O}_{2}$ adsorbed on $\mathrm{Au}_{8} @ \mathrm{BN} / \mathrm{Au}(111)$ system: (a) $\mathrm{O}_{2}$ adsorption at the corner of $\mathrm{Au}_{8}$; (b) double-bridge configuration of the adsorbed $\mathrm{O}_{2}$. The distances are given in Angstroms.

Adsorption and activation of $\mathrm{O}_{2}$ on the catalytic material is the first and one of the most important step for ORR. We have found that $\mathrm{O}_{2}$ readily adsorbs on the $\mathrm{Au}_{8} @ \mathrm{BN} / \mathrm{Au}(111)$ system at the corner atom of $\mathrm{Au}_{8}$ with the adsorption energy of $E_{a d}=-0.40 \mathrm{eV}$, and in a double-bridge configuration, bridging two Au and two B atoms at the perimeter interface of the supported $\mathrm{Au}_{8}$ and the BN layer with $E_{a d}=-0.32 \mathrm{eV}$, as shown in Figures $1 \mathrm{a}$ and $1 \mathrm{~b}$, respectively. In both cases the adsorbed oxygen molecule is highly activated. It is well established that the catalytic activation of the adsorbed oxygen and stretching of the $\mathrm{O}-\mathrm{O}$ bond occurs due to the partial population of the antibonding $2 \pi^{*}$ orbital of $\mathrm{O}_{2}$. Such a mechanism of the charge-transfer-mediated activation of the oxygen molecule adsorbed on gold clusters has been intensively studied [36,81,87-94]. The calculated adsorption energies of $\mathrm{O}_{2}$ to $\mathrm{Au}_{8} @ \mathrm{~h}-\mathrm{BN} / \mathrm{Au}(111)$ are close to the experimental values known for the low coverage $\mathrm{O}_{2}$ adsorption to $\mathrm{Pt}(111)$ surface, $-0.3 \mathrm{eV}-$ $-0.5 \mathrm{eV}$, determined by the low-temperature thermal desorption spectroscopy and electron energy-loss spectroscopy methods [95-97]. Note that neither a neutral free $\mathrm{Au}_{8}$ cluster nor a stand-alone h-BN/Au(111) system is active for $\mathrm{O}_{2}$ adsorption. As we have already mentioned interaction between $\mathrm{h}-\mathrm{BN}$ and transitionmetal occurs due to the metal-d $\mathrm{BN}-\pi$ hybridization at the $\mathrm{h}-\mathrm{BN} /$ metal interface. Adding gold particle on the $\mathrm{BN} / \mathrm{Au}(111)$ surface would result in increase of the density of electronic states (DOS) near the Fermi level promoting oxygen adsorption [35,38]. The Bader charge analysis shows that $\mathrm{Au}_{8}$ on $\mathrm{h}-\mathrm{BN} / \mathrm{Au}(111)$ possesses small positive charge of $0.5 \mathrm{e}$, where e is an elementary charge. Small charge transfer from $\mathrm{Au}_{8}$ to the support breaks its electronic shell closure and promotes interaction with molecular oxygen. The ability of free cationic gold clusters to adsorb and activate $\mathrm{O}_{2}$ has been recently discussed [83]. Therefore interaction of $\mathrm{Au}_{8}$ with the h-BN/Au(111) support is crucial for formation of the active sites for $\mathrm{O}_{2}$ adsorption.
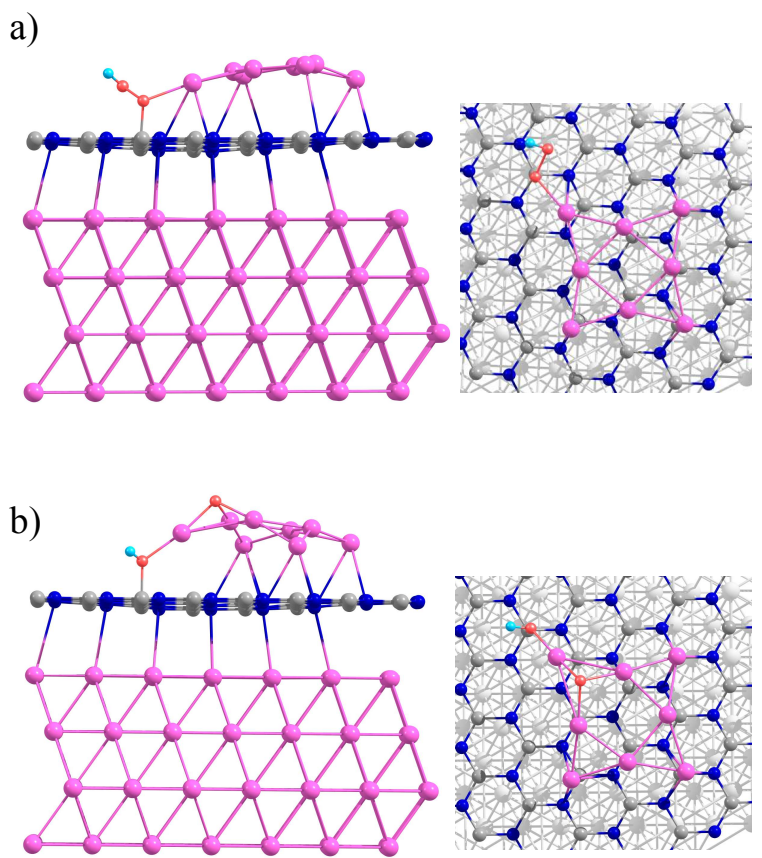

Fig. 2 Side (left) and top (right) views of the optimized geometries of $\mathrm{OOH}$ adsorbed on $\mathrm{Au}_{8} @ \mathrm{BN} / \mathrm{Au}(111)$ system: (a) $\mathrm{OOH}$ molecular adsorption; (b) $\mathrm{OOH}$ dissociation.

First proton-electron transfer to the adsorbed $\mathrm{O}_{2}{ }^{*}$ leads to formation of the hydroperoxyl $\mathrm{OOH}^{*}$ intermediate on the surface. Figure 2a presents optimized structure $\mathrm{OOH}^{*}$ adsorbed on $\mathrm{Au}_{8} @$ h-BN/Au(111). It is seen from Figure 2a that $\mathrm{OOH}^{*}$ adsorbs at the vertex atom of $\mathrm{Au}_{8}$ on $\mathrm{h}-\mathrm{BN} / \mathrm{Au}(111)$ surface bridging one $\mathrm{Au}$ atom of the cluster and the $\mathrm{B}$ atom on the support, which protrudes above the nearest $\mathrm{N}$ atoms of the surface by $0.3 \AA$. Thus the perimeter interface between the cluster and the support plays an important role of the active sites for $\mathrm{OOH}^{*}$ adsorption. The calculated $\mathrm{O}-\mathrm{O}$ bond length in $\mathrm{OOH}^{*}$ is $1.48 \AA$, and enlarged consid- 
erably in comparison with the $\mathrm{O}-\mathrm{O}$ bond length in a free $\mathrm{OOH}$ radical, $1.35 \AA$. The weakening of the $\mathrm{O}-\mathrm{O}$ bond should promote dissociation of $\mathrm{OOH}^{*}$ onto $\mathrm{O}^{*}$ and $\mathrm{OH}^{*}$ fragments. Calculations demonstrate $\mathrm{OOH}^{*}$ binds to h-BN with $E_{a d}=-1.43 \mathrm{eV}$ in respect to the free $\mathrm{OOH}$ radical. This value is larger than theoretically obtained adsorption energy of $\mathrm{OOH}$ to the pure h-BN $/ \mathrm{Au}(111)$ surface, $-0.93 \mathrm{eV}$, however, in the case of $\mathrm{Au}_{8} @ \mathrm{~h}-\mathrm{BN} / \mathrm{Au}(111)$ catalyst dissociation of $\mathrm{OOH}^{*}$ into $\mathrm{O}^{*}$ and $\mathrm{OH}^{*}$ is favorable energetically contrary to the h-BN/Au(111) surface. Our calculations demonstrate that deposition of $\mathrm{Au}_{8}$ cluster (which is inert towards $\mathrm{O}_{2}$ activation in its free form due to the closed electronic shell structure) on the h-BN/Au(111) surface results in formation of the highly reactive interface adsorption sites for activation of $\mathrm{O}-\mathrm{O}$ bond in $\mathrm{O}_{2}{ }^{*}$ and $\mathrm{OOH}^{*}$. It is favorable energetically that activated $\mathrm{OOH}^{*}$ intermediate dissociates on $\mathrm{Au}_{8} @ \mathrm{~h}-\mathrm{BN} / \mathrm{Au}$ (111) leads to the structure shown in Figure $2 \mathrm{~b}$. Here $\mathrm{OH}^{*}$ intermediate adsorbs on top of $\mathrm{B}$ atom and interacts with $\mathrm{Au}$ atom at the cluster vertex, while $\mathrm{O}^{*}$ moves ontop of the $\mathrm{Au}_{8}$ capping $3 \mathrm{Au}$ atoms at the cluster edge. The dissociation of $\mathrm{OOH}^{*}$ is followed by reduction of $\mathrm{O}^{*}$ to $\mathrm{OH}^{*}$ as a result of the second proton-electron transfer. Finally two $\mathrm{OH}^{*}$ intermediates are reduced to water.

\subsection{Energetics of the oxygen reduction reaction}

Figure 3 demonstrates the change in free energy, $\Delta G$, calculated along the ORR pathways for h-BN/Au(111) (black line) and $\mathrm{Au}_{8} @ \mathrm{BN} / \mathrm{Au}(111)$ (red line with triangles) systems. Here, $\Delta G$ takes into account zero-point energy corrections, entropy and solvent effects on the adsorption energies of all ORR intermediates as described in section 2 .

Our calculations demonstrate that presence of the $\mathrm{Au}_{8}$ cluster on the $\mathrm{h}-\mathrm{BN} / \mathrm{Au}(111)$ support results in a mild stabilization of $\mathrm{O}_{2}{ }^{*}, \mathrm{OOH}^{*}$ and $\mathrm{OH}^{*}$ intermediates by $\sim 0.5 \mathrm{eV}$, and drastic stabilization of $\mathrm{O}^{*}$ by $\sim 1.6 \mathrm{eV}$ in comparison with adsorption on the pure h-BN/Au(111) surface. Such stabilization of $\mathrm{O}^{*}$ at the perimeter interface of $\mathrm{Au}_{8}$ and h-BN/Au(111) support energetically promotes $\mathrm{OOH}^{*}$ dissociation and opens pathway for the 4-electron oxygen reduction. Indeed, Figure 3 shows that in the case of $\mathrm{Au}_{8}$ cluster deposited on h-BN/Au(111) surface $\Delta G$ decreases along the whole reaction pathway making reduction of oxygen to water favorable energetically in a contrast to the pure h-BN/Au(111) surface.

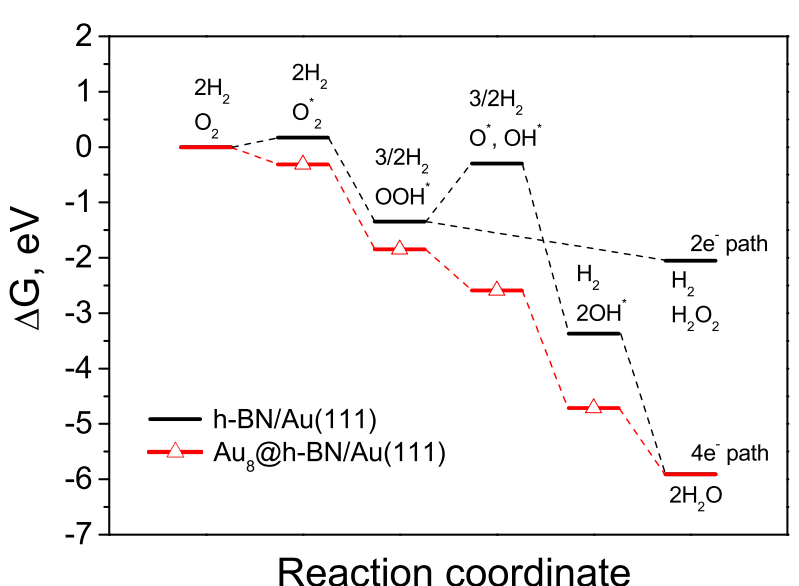

Fig. 3 Change in free energy, $\Delta G$, calculated along the ORR pathways for h-BN/Au(111) (black line) and $\mathrm{Au}_{8} @ \mathrm{~h}-$ $\mathrm{BN} / \mathrm{Au}(111)$ (red line with triangles) systems.

\section{Conclusions}

It is demonstrated on the example of a small planar $\mathrm{Au}_{8}$ cluster that gold nanoparticles deposited on the h-BN/Au(111) surface provide catalytically active sites for effective ORR. It is shown that stabilization of oxygen at the perimeter interface between $\mathrm{Au}-\mathrm{NP}$ and h$\mathrm{BN} / \mathrm{Au}(111)$ support promotes $\mathrm{OOH}^{*}$ dissociation opening the effective 4-electron pathway of ORR with formation of $\mathrm{H}_{2} \mathrm{O}$. Therefore we suggest that the increase in the perimeter interface area between the supported $\mathrm{Au}-\mathrm{NP}$ and the surface would result in increase of the ORR activity. Such increase in the perimeter interface can be achieved by decrease in size of Au-NP.

Acknowledgements This work was supported by the Japan Society for the Promotion of Science (JSPS KAKENHI Grants 15K05387 and 16KT0047); the FLAGSHIP2020 program supported by the Ministry of Education, Culture, Sports, Science and Technology (MEXT), Japan within the priority study5 (Development of new fundamental technologies for high-efficiency energy creation, conversion/storage and use); and the Development of Environmental Technology using Nanotechnology program from MEXT. The computations were performed at the Research Center for Computational Science, Okazaki, and the Numerical Materials Simulator at NIMS, Tsukuba, Japan.

\section{References}

1. M. Winter, R.J. Brodd, Chem. Rev. 104, 4245 (2004)

2. M. Shao, Q. Chang, J.P. Dodelet, R. Chenitz, Chem. Rev. 116, 3594 (2016)

3. H.A. Gasteiger, N.M. Marković, Science 324, 48 (2009)

4. N.M. Marković, T.J. Schmidt, V. Stamenković, P.N. Ross, Fuel Cells 1, 105 (2001)

5. V.R. Stamenkovic, B. Fowler, B.S. Mun, G. Wang, P.N. Ross, C.A. Lucas, N.M. Marković, Science 315, 493 (2007) 
6. M.D. Allendorf, Nature Energy 1, 16058 (2016)

7. G. Wu, P. Zelenay, Acc. Chem. Res. 46, 1878 (2013)

8. W. Chen, J. Kim, S. Sun, S. Chen, J. Phys. Chem. C 112, 3891 (2008)

9. J. Zhang, H. Yang, J. Fang, S. Zou, Nano Lett. 10, 638 (2010)

10. Y. Shao, J. Liu, Y. Wang, Y. Lin, J. Mater. Chem. 19, $46(2009)$

11. J. Suntivich, H.A. Gasteiger, N. Yabuuchi, H. Nakanishi, J.B. Goodenough, Y. Shao-Horn, Nat. Chem. 3, 546 (2011)

12. Y.J. Wang, D.P. Wilkinson, J. Zhang, Chem. Rev. 111, 7625 (2011)

13. B. Cao, G.M. Veith, R.E. Diaz, J. Liu, E.A. Stach, R.R. Adzic, P.G. Khalifah, Angew. Chem. Int. Ed. 52, 10753 (2013)

14. Y. Maekawa, A. Ishihara, J.H. Kim, S. Mitsushima, K.i. Ota, Electrochemical and Solid-State Letters 11, B109 (2008)

15. G. Zhong, H. Wang, H. Yu, F. Peng, Fuel Cells 13, 387 (2013)

16. U.I. Kramm, M. Lefévre, N. Larouche, D. Schmeisser, J.P. Dodelet, J. Am. Chem. Soc. 136, 978 (2014).

17. E.F. Holby, P. Zelenay, Nano Energy 29, 54 (2016).

18. J.A. Varnell, E.C.M. Tse, C.E. Schulz, T.T. Fister, R.T. Haasch, J. Timoshenko, A.I. Frenkel, A.A. Gewirth, Nat. Comm. 7, $12582(2016)$

19. M.J. Workman, M. Dzara, C. Ngo, S. Pylypenko, A. Serov, S. McKinney, J. Gordon, P. Atanassov, K. Artyushkova, Journal of Power Sources 348, 30 (2017)

20. T. Wang, D. Gao, J. Zhuo, Z. Zhu, P. Papakonstantinou, Y. Li, M. Li, Chemistry - A European Journal 19, 11939 (2013)

21. Y. Hu, D.H.C. Chua, Sci. Rep. 6, 28088 (2016)

22. R.A. Sidik, A.B. Anderson, N.P. Subramanian, S.P. Kumaraguru, B.N. Popov, J. Phys. Chem. B 110, 1787 (2006)

23. J.i. Ozaki, T. Anahara, N. Kimura, A. Oya, Carbon 44, $3358(2006)$

24. K. Gong, F. Du, Z. Xia, M. Durstock, L. Dai, Science 323, $760(2009)$

25. R. Liu, D. Wu, X. Feng, K. Müllen, Angew. Chem. Int. Ed. 49, 2565 (2010)

26. M. Zhou, H.L. Wang, S. Guo, Chem. Soc. Rev. 45, 1273 (2016)

27. T. Ikeda, M. Boero, S.F. Huang, K. Terakura, M. Oshima, J.i. Ozaki, J. Phys. Chem. C 112, 14706 (2008)

28. T. Ikeda, M. Boero, S.F. Huang, K. Terakura, M. Oshima, J.i. Ozaki, S. Miyata, J. Phys. Chem. C 114, 8933 (2010)

29. L. Yu, X. Pan, X. Cao, P. Hu, X. Bao, J. Catal. 282, 183 (2011)

30. L. Qu, Y. Liu, J.B. Baek, L. Dai, ACS Nano 4, 1321 (2010)

31. S.F. Huang, K. Terakura, T. Ozaki, T. Ikeda, M. Boero, M. Oshima, J.i. Ozaki, S. Miyata, Phys. Rev. B 80, 235410 (2009)

32. R. Arenal, O. Stéphan, M. Kociak, D. Taverna, A. Loiseau, C. Colliex, Phys. Rev. Lett. 95, 127601 (2005)

33. D. Golberg, Y. Bando, Y. Huang, T. Terao, M. Mitome, C. Tang, C. Zhi, ACS Nano 4, 2979 (2010)

34. M. Gao, A. Lyalin, T. Taketsugu, Catalysts 1, 18 (2011)

35. M. Gao, A. Lyalin, T. Taketsugu, J. Phys. Chem. C 116, $9054(2012)$

36. M. Gao, A. Lyalin, T. Taketsugu, Int. J. Quantum Chem. 113, 443 (2013)
37. M. Gao, A. Lyalin, T. Taketsugu, J. Chem. Phys. 138, $034701(2013)$

38. A. Lyalin, M. Gao, T. Taketsugu, Chem. Rec. 16, 2324 (2016)

39. A. Lyalin, A. Nakayama, K. Uosaki, T. Taketsugu, Phys. Chem. Chem. Phys. 15, 2809 (2013)

40. A. Lyalin, A. Nakayama, K. Uosaki, T. Taketsugu, J. Phys. Chem. C 117, 21359 (2013)

41. A. Lyalin, A. Nakayama, K. Uosaki, T. Taketsugu, Top. Catal. 57, 1032 (2014)

42. H. Zeng, C. Zhi, Z. Zhang, X. Wei, X. Wang, W. Guo, Y. Bando, D. Golberg, Nano Lett. 10, 5049 (2010)

43. S. Azevedo, J.R. Kaschny, C.M. de Castilho, F. de Brito Mota, Eur. Phys. J. B 67, 507 (2009)

44. A.B. Preobrajenski, A.S. Vinogradov, N. Mårtensson, Surf. Sci. 582, 21 (2005)

45. A.B. Preobrajenski, S.A. Krasnikov, A.S. Vinogradov, M.L. Ng, T. Käämbre, A.A. Cafolla, N. Mårtensson, Phys. Rev. B 77, 085421 (2008)

46. A.B. Preobrajenski, A.S. Vinogradov, N. Mårtensson, Phys. Rev. B 70, 165404 (2004)

47. K. Uosaki, G. Elumalai, H. Noguchi, T. Masuda, A. Lyalin, A. Nakayama, T. Taketsugu, J. Am. Chem. Soc. 136, 6542 (2014)

48. G. Elumalai, H. Noguchi, K. Uosaki, Phys. Chem. Chem. Phys. 16, 13755 (2014)

49. K. Uosaki, G. Elumalai, H.C. Dinh, A. Lyalin, T. Taketsugu, H. Noguchi, Sci. Rep. 6, 32217 (2016)

50. G. Elumalai, H. Noguchi, A. Lyalin, T. Taketsugu, K. Uosaki, Electrochem. Commun. 66, 53 (2016)

51. M. Haruta, T. Kobayashi, H. Sano, N. Yamada, Chem. Lett. 16, 405 (1987)

52. M. Haruta, Catal. Today 36, 153 (1997)

53. M. Haruta, The Chemical Record 3, 75 (2003)

54. G.J. Hutchings, M. Brust, H. Schmidbaur, Chem. Soc Rev. 37, 1759 (2008)

55. M. Haruta, Faraday Discuss. 152, 11 (2011)

56. Z. Wu, R.E. Cohen, Phys. Rev. B 73, 235116 (2006)

57. F. Tran, R. Laskowski, P. Blaha, K. Schwarz, Phys. Rev. B 75, $115131(2007)$

58. R. Laskowski, P. Blaha, K. Schwarz, Phys. Rev. B 78, 045409 (2008)

59. R. Laskowski, P. Blaha, Phys. Rev. B 81, 075418 (2010)

60. M.H. Khan, S.S. Jamali, A. Lyalin, P.J. Molino, L. Jiang, H.K. Liu, T. Taketsugu, Z. Huang, Adv. Mater. 29, $1603937(2017)$

61. N. Troullier, J.L. Martins, Phys. Rev. B 43, 1993 (1991)

62. J.A. Nelder, R. Mead, The Computer Journal 7, 308 (1965)

63. D. Sánchez-Portal, P. Ordejón, E. Artacho, J.M. Soler, Int. J. Quantum Chem. 65, 453 (1997)

64. J.M. Soler, E. Artacho, J.D. Gale, A. García, J. Junquera, P. Ordejón, D. Sánchez-Portal, J. Phys.: Condens. Matter 14, $2745(2002)$

65. D. Sánchez-Portal, P. Ordejón, E. Canadell, Structure and Bonding 113, 103 (2004)

66. H.J. Monkhorst, J.D. Pack, Phys. Rev. B 13, 5188 (1976)

67. C.S. Yoo, J. Akella, H. Cynn, M. Nicol, Phys. Rev. B 56 , 140 (1997)

68. R.W.G. Wyckoff, Crystal Structures, vol. 1 (John Wiley \& Sons, 1963)

69. R. Bader, Atoms in Molecules: A Quantum Theory (Oxford University Press, New York, 1990)

70. G. Henkelman, A. Arnaldsson, H. Jónsson, Comput. Mater. Sci. 36, 354 (2006)

71. J.K. Nørskov, J. Rossmeisl, A. Logadottir, L. Lindqvist, J.R. Kitchin, T. Bligaard, H. Jónsson, J. Phys. Chem. B 108, $17886(2004)$ 
72. T. Jacob, Fuel Cells 06, 159 (2006)

73. J.A. Keith, G. Jerkiewicz, T. Jacob, ChemPhysChem 11, 2779 (2010)

74. J.A. Keith, T. Jacob, Angew. Chem. Int. Ed. 49, 9521 (2010)

75. B. Hammer, J. Nørskov, Surf. Sci. 343, 211 (1995)

76. B. Hammer, J.K. Nørskov, Adv. Catal. 45, 71 (2000)

77. P. Vassilev, M.T.M. Koper, J. Phys. Chem. C 111, 2607 (2007)

78. J. Rossmeisl, J.K. Nørskov, C.D. Taylor, M.J. Janik, M. Neurock, J. Phys. Chem. B 110, 21833 (2006)

79. K.Y. Yeh, M.J. Janik, J. Comput. Chem. 32, 3399 (2011)

80. V. Tripković, E. Skúlason, S. Siahrostami, J.K. Nørskov, J. Rossmeisl, Electrochim. Acta 55, 7975 (2010)

81. A. Lyalin, T. Taketsugu, J. Phys. Chem. C 113, 12930 (2009)

82. A.P. Woodham, A. Fielicke, Angew. Chem. Int. Ed. 53, $6554(2014)$

83. M. Gao, D. Horita, Y. Ono, A. Lyalin, S. Maeda, T. Taketsugu, J. Phys. Chem. C 121, 2661 (2017)

84. H. Häkkinen, B. Yoon, U. Landman, X. Li, H. Zhai, L. Wang, Phys. Chem. A 107, 6168 (2003)

85. L. Xiao, B. Tollberg, X. Hu, L. Wang, J. Chem. Phys. 124, 114309 (2006)

86. B. Assadollahzadeh, P. Schwerdtfeger, J. Chem. Phys. 131, 064306 (2009)

87. H. Häkkinen, U. Landman, J. Am. Chem. Soc. 123, 9704 (2001)

88. B. Yoon, H. Häkkinen, U. Landman, J. Phys. Chem. A 107, 4066 (2003)

89. L.D. Socaciu, J. Hagen, T.M. Bernhardt, L. Wöste, U. Heiz, H. Häkkinen, U. Landman, J. Am. Chem. Soc. 125, 10437 (2003)

90. H. Häkkinen, S. Abbet, A. Sanchez, U. Heiz, U. Landman, Angew. Chem. Int. Ed. 42, 1297 (2003)

91. X. Ding, Z. Li, J. Yang, J.G. Hou, Q. Zhu, J. Chem. Phys. 120, 9594 (2004)

92. E. Fernández, P. Ordejón, L.C. Balbás, Chem. Phys. Lett. 408, 252 (2005)

93. R. Coquet, K.L. Howard, D.J. Willock, Chem. Soc. Rev. 37, 2046 (2008)

94. A. Lyalin, T. Taketsugu, J. Phys. Chem. Lett. 1, 1752 (2010)

95. J.L. Gland, B.A. Sexton, G.B. Fisher, Surf. Sci. 95, 587 (1980)

96. C. Campbell, G. Ertl, H. Kuipers, J. Segner, Surf. Sci. 107, $220(1981)$

97. P.D. Nolan, B.R. Lutz, P.L. Tanaka, J.E. Davis, C.B. Mullins, J. Chem. Phys. 111, 3696 (1999) 